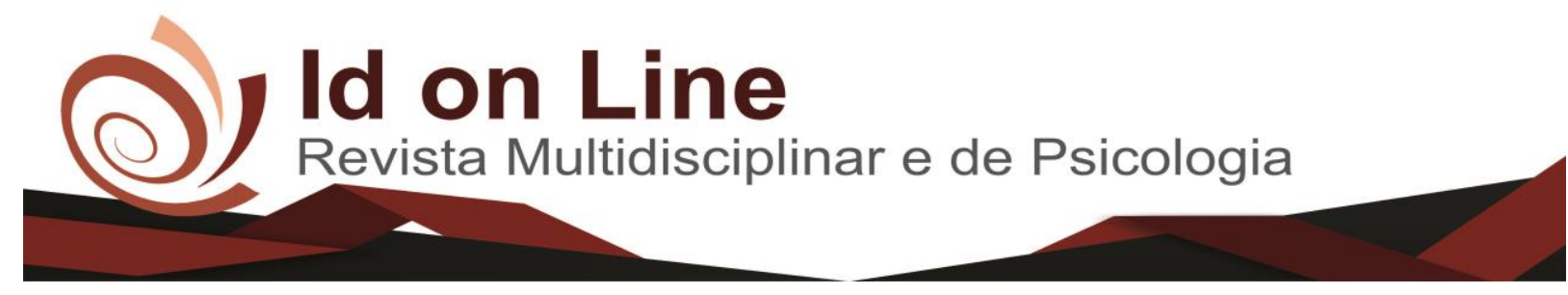

Artigo

\title{
Políticas Públicas para micro e minigeração de energia solar no estado do Ceará: um estudo levando-se em consideração o contexto nacional e municípios no semiárido cearense
}

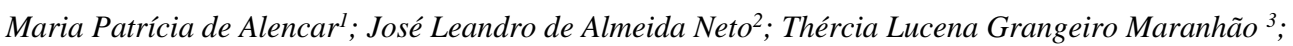 \\ Cristiano Viana Cavalcanti Castellão Tavares ${ }^{4}$
}

\begin{abstract}
Resumo: No Ceará e em alguns municípios, seja em residências ou empresas, surgem iniciativas para produção de energia limpa, fundamentalmente na produção de energia solar. O objetivo geral do trabalho é investigar as políticas públicas existentes no Estado do Ceará e apresentar sugestões nas esferas municipal, estadual e federal para o incentivo à utilização da energia solar. A pesquisa caracteriza-se como básica, exploratória, descritiva, qualitativa e estudo de campo. O estudo foi realizado em alguns municípios do Semiárido Cearense, sendo eles Juazeiro do Norte, Acopiara, Altaneira, Farias Brito, Jardim, Missão Velha e Várzea Alegre, no período de 01 a 30 de agosto de 2017. Os sujeitos da pesquisa foram 12 atores públicos e privados ligados ao assunto energia solar. $\mathrm{O}$ local e sujeitos da pesquisa foram selecionados por conveniência e acessibilidade. O instrumento de coleta de dados utilizado foi a entrevista semiestruturada. A análise dos dados foi feita adotando-se a técnica de análise de conteúdo. Como principais resultados destacam-se: os gestores têm uma boa visão das políticas públicas existentes, concordam que a Região do Cariri e o Estado do Ceará apresentam potencial energético solar, que os impostos ainda atuam como empecilhos para os investimentos. As sugestões foram a criação de um fundo de investimentos específico para incrementar a matriz, o financiamento com taxas competitivas para equipamentos importados, utilização do FGTS (Fundo de Garantia do Tempo de Serviço) ou abatimento do imposto de renda para investimentos para pessoas físicas e a criação de um IPTU (Imposto Predial e Territorial Urbano) verde com valores menores para empreendimentos com esta matriz.
\end{abstract}

Palavras-chave: Preocupação Ambiental. Políticas Públicas. Energia Solar. Autossuficiência Energética.

\section{Public policies for micro and solar minigeneration energy in the state of Ceará: a study taking into account the national context and municipalities in Ceará semiarid region}

\begin{abstract}
In Ceará and in some towns, whether in homes or companies, there are initiatives to produce clean energy, mainly in the production of solar energy. The overall objective of this study is to investigate the existing policy in the State of Ceará and make suggestions on municipal, state and federal levels to encourage the use of solar energy. The present research is characterized as basic, exploratory, descriptive, qualitative and field study. The study was conducted in some districts in Ceará's semiarid, such as Juazeiro do Norte, Acopiara, Altaneira, Farias Brito, Jardim, Missão Velha and Várzea Alegre, with a time window from 01 to 30 August 2017. The
\end{abstract}

\footnotetext{
${ }^{1}$ Graduanda do Curso de Administração do Centro Universitário Doutor Leão Sampaio (UNILEÃO) - Juazeiro do Norte-CE, Brasil, patriciaalencar133@gmail.com;

${ }^{2}$ Professor do Centro Universitário Doutor Leão Sampaio (UNILEÃO), Mestrando em Desenvolvimento Sustentável pela Universidade Federal do Cariri (UFCA), Coordenador dos Cursos de Gestão de Recursos Humanos e Gestão Comercial na Unileão, Juazeiro do Norte-CE, Brasil, leandro@leaosampaio.edu.br;

${ }^{3}$ Psicóloga. Professora do Centro Universitário Doutor Leão Sampaio (UNILEÃO).Mestra em Ciências da Saúde pela Faculdade de Medicina do ABC (FMABC). thercia@leaosampaio.edu.br;

${ }^{4}$ Professor Orientador do Centro Universitário Doutor Leão Sampaio (UNILEÃO), Doutorando em Desenvolvimento Sustentável pela Universidade de Brasília (UNB), Mestre em Administração de Empresas pela Universidade Estadual (UECE), Administrador na Universidade Federal do Cariri (UFCA), Juazeiro do Norte-CE, Brasil, c.castellao@gmail.com.
} 
subjects of the research were 12 public and private agents who were connected to the subject in question. The site and subjects of the survey were selected regarding convenience and accessibility. The instrument of data collection used was a semi-structured interview. Data analysis was performed adopting the technique of content analysis. The main results were: managers acknowledge the existing public policy, they agree that the region of Cariri and the State of Ceará have solar energy potential, and that taxes still bring obstacles to investments. Furthermore, they suggested the creation of a specific investment fund to increase the matrix, financing, at competitive rates, imported equipment, use of FGTS (stands for Service Assurance Fund) or reduction of income tax for independent investors, and finally, the creation of a green property tax with lower values for companies with this matrix.

Keywords: Environmental Concern. Public policy. Solar energy. Energy Self-sufficiency.

\section{Introdução}

A preocupação ambiental ocupa posição de destaque como tema nos acordos ambientais internacionais, nas organizações públicas e privadas, nas organizações do terceiro setor e na academia, como objeto de estudo em artigos, dissertações, teses e livros.

Cientistas apontam que alguns impactos já são inevitáveis e alguns já estão sendo sentidos. Georgescu-Roegen (2012) na sua obra "O Decrescimento", alertava para a necessidade da descarbonização do sistema energético e afirmava que deveríamos sair da energia de estoque para energia de fluxo, de fácil acesso.

A irradiação média anual brasileira varia entre 1.200 e $2.400 \mathrm{kWh} / \mathrm{m}^{2} / \mathrm{ano}$, bem acima da média da Europa. O MME destaca que até 2018 o Brasil deverá estar entre os 20 países com maior geração de energia solar do mundo (MINISTÉRIO DE MINAS E ENERGIA - MME, 2015).

No Ceará e em alguns municípios seja em residências ou empresas, surgem iniciativas para produção de energia limpa. Fundamentalmente na produção de energia solar, além da possibilidade da autossuficiência energética para as empresas, há uma expectativa de impacto positivo no meio ambiente. Importante ressaltar que estas atividades de sustentabilidade podem também contribuir para a transformação social da comunidade, assim as boas práticas podem gerar emprego e renda para a região.

Diante das oportunidades da irradiação solar no semiárido nordestino, especificamente no Estado do Ceará, e a possibilidade de utilização desta fonte renovável como estratégia de diversificação da matriz energética e contribuir para diminuição das emissões de $\mathrm{CO}_{2}$ das termoelétricas, o trabalho visa encontrar resposta para a seguinte problemática. Quais as 
políticas públicas existentes para que haja o desenvolvimento da micro e minigeração de energia solar no Estado do Ceará e quais sugestões poderiam ser fornecidas na esfera, federal, estadual e em alguns municípios no Semiárido Cearense para o incremento desta matriz?

Para responder a problemática acima, algumas hipóteses foram levantadas a fim de servir como respostas prévias e depois pode-se ou não ser refutadas através da coleta e análise de dados, sendo estas: os entrevistados mostrarão conhecimento das políticas públicas e apresentarão sugestões; os entrevistados não mostrarão conhecimento das políticas públicas e não apresentarão sugestões; os entrevistados mostrarão conhecimento parcial das políticas públicas e não apresentarão sugestões; os entrevistados mostrarão conhecimento parcial das políticas públicas e apresentarão sugestões.

A pesquisa possui como objetivo geral investigar as políticas públicas existentes no Estado do Ceará e apresentar sugestões nas esferas municipal, estadual e federal para o incentivo à utilização da energia solar. E como objetivos específicos: conceituar o que é política pública e o que é a tecnologia de energia solar; verificar o conhecimento das políticas públicas por parte dos entrevistados; verificar a produção atual da micro e mini geração de energia solar instalada no Estado do Ceará e seu potencial de crescimento; identificar pontos críticos que possam estar dificultando a disseminação da tecnologia solar; identificar potenciais e sugestões para a disseminação da tecnologia de energia solar.

O Estado do Ceará e a Região do Semiárido vem sofrendo com o problema da seca nos últimos anos. Este problema,com escassez hídrica e aumento de temperatura pode estar inteiramente ligado ao aquecimento global como também relacionado aos níveis de emissão de $\mathrm{CO}_{2}$ ao longo das últimas décadas. Tais efeitos, trazem diversas consequências, dentre elas um alto custo ambiental, no acionamento das termoelétricas, pois precisa ser garantida a geração e fornecimento de energia elétrica. Neste caso, quanto mais se utiliza das termoelétricas, mais poluição é disseminada no meio ambiente, resultando também em uma energia mais cara, pois os custos inerentes a este processo é transferido para os consumidores.

Diante do que foi exposto, surge também o interesse em realizar esta pesquisa pela oportunidade que o semiárido nordestino apresenta frente a forte vocação para o desenvolvimento de energia solar. Quando esta fonte renovável se torna cada vez mais utilizada traz também como consequência e benefícios a geração de emprego, isto é traz o fortalecimento deste item, como trabalha os investimentos e crescimento da economia de um país impactandoa positivamente. 
O estudo da temática energia solar é fundamental, principalmente no que se refere a políticas públicas que visem incentivar o uso desta fonte de energia e os desafios que precisam ser vencidos, torna-se relevante para auxiliar os governantes, poder legislativo e sociedade civil a identificar e planejar quais mudanças legais necessitam ser implantadas ou implementada com a finalidade de tornar esta fonte alternativa de energia mais utilizada no estado, contribuindo para o desenvolvimento sustentável.

\section{Referencial Teórico}

Esta seção apresenta a revisão da literatura a respeito das temáticas que compõem o trabalho. No intuito de conferir mais clareza à apresentação dos temas abordados, esta seção é estruturada em três subseções. A subseção 2.1 refere-se à Tecnologia de Energia Solar, contemplando o tópico 2.1.1 de Micro e Minigeração de Energia Solar. Na sequência, a subseção 2.2 aborda a Energia Solar no Ceará contemplando o tópico 2.2.1 da Energia Solar no contexto dos Acordos Internacionais. Por fim, a subseção 2.3 expõe questões sobre Políticas Públicas, contemplando contextualização, definições e importância da mesma.

\section{Tecnologia de Energia Solar}

A energia solar é uma fonte importante para a existência do ser vivo, pois está presente em quase ou em todos os processos da vida na terra, esta é uma fonte de energia natural e necessária para o processo de sobrevivência das plantas, das pessoas, dos animais e em geral de toda e qualquer forma de vida. Sendo assim ela pode futuramente vir a ser a principal forma de energia como pode vir a substituir as fontes de energia tradicionalmente existentes.

Ao passar dos anos novas tecnologias, avanços e invenções em diferentes áreas são criadas e apresentadas ao mercado e às nossas vidas. Determinadas tecnologias tem o poder de transformar a vida das pessoas, impactando milhões delas e vindo a modificar o relacionamento em sociedade. Um estudo destaca uma das cinco novas tecnologias que podem revolucionar o mundo em breve, que é a tecnologia da energia solar, enfatizando a necessidade de criar e 
aperfeiçoar novas fontes de energia conforme o crescimento da população mundial e o aumento da demanda (CASTELLI, 2015).

A energia solar provém da radiação solar e pode ser utilizada ou aproveitada basicamente por dois tipos de processos ou efeitos: o térmico e fotovoltaico (KEMERICH et al.,2016). Esta pesquisa concentra esforços no processo fotovoltaico residencial ou em empresas. Segundo Carvalho e Calvette (2010), o pressuposto da energia solar é usar o sol para ir ao encontro das necessidades energéticas do planeta.

O processo de conversão direta da energia solar em energia elétrica acontece ou pode ser observado pelos efeitos da radiação (calor e luz) sobre determinados materiais, particularmente pelos chamados semicondutores, como o fotovoltaico. O efeito fotovoltaico caracteriza-se pelos fótons contidos na luz solar onde são convertidos em energia elétrica através da utilização das chamadas células solares (AGÊNCIA NACIONAL DE ENERGIA ELÉTRICA - ANEEL, 2017).

Uma das formas de se conseguir energia elétrica através do sol é por um sistema chamado fotovoltaico. Por meio desse sistema há o processo de conversão da luz solar em energia elétrica, isso ocorre através do uso dos chamados módulos fotovoltaicos ou painéis interligados entre si (BIGGI, 2013).

Carvalho e Calvette (2010) salientam que a fonte alternativa de energia solar é limpa e seu uso pode atender as necessidades energéticas dos continentes com a vantagem de ser inesgotável. Os autores destacam o empenho de muitas pessoas que estão em laboratórios e universidades em busca de novos estudos, descobertas e pesquisas comprovadas sobre energia solar, enfatizando a importância desta tecnologia ser colocada a serviço da humanidade. Georgescu - Roegen (2012, p. 120) afirmava, que "o uso da energia solar não comporta maiores riscos ou pontos de interrogação, ela é indiscutível e que a sobrevivência da raça humana depende desta fonte alternativa.

Knob (2013) converge com os demais autores e informa que a energia solar fotovoltaica trata de uma energia percebida como limpa e renovável e pode ser utilizada perto ao local de consumo. Esta baseia-se numa fonte considerada como inesgotável, chamada sol. O autor finaliza dizendo que neste tipo de energia encontra-se uma das mais promissoras, tornando-se uma oportunidade para atender a uma demanda energética dos próximos anos.

Aproveitar a energia solar como fonte de calor ou como fonte de luz torna-se um dos meios, caminhos ou alternativas energéticas mais promissoras e viáveis para vir a solucionar 
grande parte dos problemas relacionados a escassez de energia que a população mundial enfrenta (TORRES, 2012).

\section{Micro e Minigeração de Energia Solar}

Aproveitar a luz do sol para gerar energia para residências e empresas torna-se uma realidade, sendo assim o indivíduo ou representante de uma empresa que decide implantar esta ideia pode ser um micro e/ou mini gerador de energia. Desse modo a Aneel (2014,2016), através da resolução 482, de 17 de abril de 2012, passou a informar que qualquer consumidor brasileiro tem a oportunidade de gerar sua própria energia elétrica, tal energia pode ser conseguida através de fontes consideradas renováveis ou cogeração qualificada, como também passar a fornecer aquilo que excedeu para uma rede de distribuição local. Esta resolução trata das questões relacionadas a micro e da mini geração distribuída de energia elétrica. No cenário atual trata-se de inovações que visam aliar a economia financeira, disseminação da consciência socioambiental e o desenvolvimento da autosustentabilidade.

A Aneel $(2014,2016)$ ainda enfatiza que os incentivos voltados a geração distribuída são justificados por diversos aspectos, onde em uma visão mais ampla verifica-se a presença de benefícios importantes que o mesmo pode trazer para o sistema elétrico. Entre estes podem ser citados a possibilidade de a matriz energética ser diversificada, outro ponto a ser observado é o baixo impacto ambiental, além do processo de redução de perdas que passam a ser minimizadas, como também ocorrerá de os investimentos em expansão dos sistemas de transmissão serem adiados ou reduzidos.

Adota-se a seguinte definição de micro e minigeração:

I - Microgeração distribuída: central geradora de energia elétrica, com potência instalada menor ou igual a $75 \mathrm{~kW}$ e que utilize cogeração qualificada, conforme regulamentação da ANEEL, ou fontes renováveis de energia elétrica, conectada na rede de distribuição por meio de instalações de unidades consumidoras;

II - Minigeração distribuída: central geradora de energia elétrica, com potência instalada superior a $75 \mathrm{~kW}$ e menor ou igual a $3 \mathrm{MW}$ para fontes hídricas ou menor ou igual a $5 \mathrm{MW}$ para cogeração qualificada, conforme regulamentação da ANEEL, ou para as demais fontes renováveis de energia elétrica, conectada na rede de distribuição por meio de instalações de unidades consumidoras;

(RESOLUÇÃO NORMATIVA ANEEL No 482, DE 17 DE ABRIL DE 2012, Art. $2^{\circ}$, p.1). 
A resolução 482 veio materializar uma importante política pública que trata do incentivo da geração de energia fotovoltaica distribuída, viabilizando assim a conexão de micro e mini geradores de energia fotovoltaica a rede. A geração fotovoltaica distribuída deve se tornar ainda mais relevante dentro da matriz energética nacional, embora se faz necessário adotar políticas complementares que visem aumentar a atratividade desse tipo de investimento (NETO, MADRUGA e GEREMIAS, 2016).

\section{Energia Solar no Ceará}

O Brasil não utiliza esta fonte de energia como deveria, pois, tem-se uma riqueza natural que poderia ser melhor explorada como também pelo fato deste país possuir um elevado índice de radiação solar, neste caso destaca-se que há oportunidades para o crescimento e desenvolvimento da energia solar em território brasileiro, mostrando-se que já há políticas públicas com o objetivo de impulsionar o uso desta fonte, entretanto existe a necessidade de criar e ampliar tais políticas. Ao realizar tal ação tem-se como consequência a diversificação da matriz energética brasileira (SILVA, 2015).

Neste cenário, a região nordeste apresenta alguns estados com boas condições para a visualização da produção deste tipo de energia, dentre eles destaca-se o estado do Ceará, de maneira ampla, frente as questões geográficas, este estado tem posição próxima da linha do equador, vindo a proporcionar alta incidencia solar. Tais condições climáticas favoráveis tem atraído a presença de empresas que comercializam painés solares proporcionando um cenário atrativo para o processo de investimento na região. Segundos dados do Instituto Brasileiro de Geografia e Estatística (IBGE, 2015) o Ceará é apontado como sendo o maior destaque na geração de energia solar do Brasil, tal estado responde sozinho por $67 \%$ do total da potência outorgado no país.

Para incentivar a utilização de fontes alternativas de energia o Governo do Estado do Ceará criou o decreto $\mathrm{n}^{\mathrm{o}} 31.853$ de 14 de dezembro de 2015. Este decreto vem isentar o excedente de energia elétrica que vai para rede de distribuição proveniente da energia solar do imposto sobre circulação de produtos e serviços (ICMS). O governo acrescenta que é preciso potencializar e disseminar o uso desta fonte de energia e que muitos investimentos estão sendo realizados e precisam ser intensificados (BRASIL B, 2015). 
O Ceará teve a primeira usina de energia solar comercial da América Latina inaugurada em 2011, na cidade de Tauá, no sertão dos Inhamuns. A instalação da usina mostra que o Ceará caminha rumo ao desenvolvimento sustentável e este é só um dos passos que precisa ser trabalhado para que o estado tenha um futuro cada vez mais promissor (GOVERNO DO ESTADO DO CEARÁ, 2011).

A Cidade de Tauá no Ceará ganhou a primeira usina comercial de energia solar do Brasil, sendo escolhida devido à forte incidência solar durante todo o ano. A cidade não mediu esforços para a instalação da mesma, chegando a fornecer os operários para montar a usina. Tal projeto e empreendimento gerou muitos empregos, tendo este ponto como de extrema relevância para a cidade como para toda uma economia $(\mathrm{G} 1,2011)$.

O governo do estado acrescenta que é preciso trabalhar os incentivos para que indústrias desse tipo decidam se instalar neste estado, assim resolveu criar o Fundo de Incentivo à Energia Solar chamado de (FIES), garantindo que esta primeira indústria se instalasse no estado, e incentivando as demais empresas a pensarem na possibilidade. Com o FIES, o governo então veio abrir um crédito orçamentário para desenvolver atividades de compra de energia solar destinada aos órgãos e entidades da administração pública. Em síntese o Ceará parte na frente no País quando se refere em energia alternativa como também em relação ao FIES (GOVERNO DO ESTADO DO CEARÁ, 2011).

Foi aprovado no ano de 2016 em uma reunião ordinária do Conselho Estadual do Meio Ambiente (COEMA), ocorrida na sede da Superintendência Estadual do Meio Ambiente (SEMACE), o projeto chamado de Complexo Fotovoltaico Apodi, destacado como um dos maiores projetos focados em energia solar no Ceará, devendo ser instalado no município de Quixeré. Tal projeto foi decidido de forma unanime pelo colegiado. Este foi avaliado em R\$ 800 milhões (AMBIENTE ENERGIA, 2016).

A usina solar será instalada entre as comunidades de Bonsucesso, Boa Esperança,
Baixa do Félix e Lajedo do Mel de Quixeré, apresentando grande estrutura metálica,
com sete usinas fotovoltaicas, total de 825.300 módulos fotovoltaicos de $320,0 \mathrm{Wp}$ de
potência, em área de 825 hectares. A energia elétrica produzida no Complexo
Fotovoltaico será escoada através de uma linha de transmissão aérea, em $230 \mathrm{Kv}$ e
com apenas 215 metros de extensão, a partir da Subestação Elevadora Apodi até a
conexão com a Subestação de Quixeré (AMBIENTE ENERGIA, 2016, p.1, grifo do
autor).

A pesquisa da (Solarterra apud Picanço, 2015) mostra a análise da energia solar no Ceará onde foi feito um comparativo de radiação solar entre o Ceará, o Brasil e a Alemanha, na qual 
respectivamente tem-se como média de $\mathrm{kwh} / \mathrm{m}^{2}$.dia os valores de 5,46, 4,9 e 2,9. O autor destaca que a Alemanha é o país com maior produção de energia solar fotovoltaica. O resultado da pesquisa destaca que a radiação solar média do Ceará é $90 \%$ maior que a da Alemanha, ou seja, a média do Ceará é: $5,5 \mathrm{kwh} / \mathrm{m}^{2}$.dia, este dado vem demonstrar o quanto este estado tem potencial para crescimento e desenvolvimento desta fonte renovável.

Importante destacar que foi firmado uma parceria através da assinatura de um acordo de cooperação entre o Banco do Nordeste (BNB), a Federação das Câmaras de Dirigentes Logísticas do Ceará (FCDL-CE) e a Companhia Energética do Ceará (COELCE), para tornar viável o financiamento e implantação desta fonte de energia em empresas do Comércio do Ceará. Tal acordo visa trabalhar de forma mais intensa o FNE Sol que é a linha de financiamento à micro e minigeração distribuída de energia elétrica renovável, com a finalidade de acelerar o processo de financiamento de kits fotovoltaicos, destacando que o banco pode financiar até $100 \%$ do investimento (JORNAL O POVO, 2016).

Diante de todo o cenário apresentado e do potencial que o Brasil e o Ceará têm em relação a energia solar, é possível constatar que o Estado do Ceará está demonstrando ações de incentivo a esta matriz energética.

\section{Energia Solar no Contexto dos Acordos Internacionais}

É de suma importância ressaltar que os principais Acordos Internacionais destacam a importância do processo de descarbonização e incentivam o uso das energias renováveis, dentre elas a energia solar, com a finalizade de tornar os países e o mundo em um caminho mais sustentável e resiliente.

Nesse cenário a Organização das Nações Unidas (ONU), criou a Agenda 2030 que trata de um plano de ação global para que em 2030 seja alcançado o desenvolvimento sustentável, estabelecendo-se objetivos e metas a serem perseguidos pelos países na busca por tal desenvolvimento. Aderiram a agenda os 193 países-membros das Nações Unidas, dos quais está inserido o Brasil que aderiu em 2015. Vale ressaltar que a Agenda de Ação Global da ONU, trata de incentivos governamentais para mini e micro geração de energia limpa (ONU, AGENDA 2030). 
Os objetivos definidos podem ser caracterizados como integrados, indivisíveis e mesclados, em quem de forma equilibrada trabalham as dimensões econômica, ambiental e social, englobando e representando assim as três dimensões do desenvolvimento sustentável (ONU, AGENDA 2030). O objetivo e os pontos principais na Agenda 2030 que estão relacionados com a pesquisa são os seguintes:

Objetivo 7 - Energias renováveis. (Garantir acesso à energia barata, confiável, sustentável e renovável para todos).

7.1 Até 2030, assegurar o acesso universal, confiável, moderno e a preços acessíveis a serviços de energia.

7.2 Até 2030, aumentar substancialmente a participação de energias renováveis na matriz energética global. (ONU, AGENDA 2030).

O Acordo de Paris foi firmado em 12 de dezembro de 2015 por 195 países na Cúpula do Clima realizada na capital francesa. Esse acordo trata de um pacto global de luta contra o aquecimento global do qual é um problema mundial. O objetivo é que o aumento da temperatura seja controlado por todos os países envolvidos e destaca que um dos objetivos principais que é reduzir as emissões de $\mathrm{CO}_{2}$ em $37 \%$ até o ano de 2025. Este acordo representa o principal instrumento de cooperação internacional com ênfase no processo de redução das emissões de gases do efeito estufa (GEEs) como no processo de adaptação às mudanças climáticas globais. Este acordo tem por finalidade reduzir as consequências do aquecimento para que causem o mínimo de impacto negativo possível ao meio ambiente e a espécie humana (EL PAÍS, 2016, PALÁCIO DO PLANALTO PRESIDÊNCIA DA REPÚBLICA, 2016).

Outro ponto importante a ser observado e destacado é a síntese dos compromissos assumidos pelo Brasil no Acordo da COP21. Este compromete-se a redução de $43 \%$ de gases do efeito estufa a ser atingido até o ano de 2030.Destaca-se também o compromisso de ampliar a participação de fontes de energia renováveis na matriz energética do país, a exemplo pode-se citar a energia solar. Ao incentivar a energia solar, pode-se diminuir a utilização de energia pela termoelétrica, reduzindo-se assim as emissões de $\mathrm{CO}_{2}$ (REPÚBLICA FEDERATIVA DO BRASIL, 2017).

Observa-se que os pontos enfatizados nos acordos internacionais estão inseridos no projeto de pesquisa. 


\section{Políticas Públicas}

O assunto políticas públicas é pauta nas atuais discussões envolvendo a temática desenvolvimento sustentável e nos acordos internacionais sobre o clima, tornando-se relevante a apresentação de seus conceitos por diversos autores.

Segundo Bursztyn e Bursztyn (2013) política pública trata-se de um conceito interdisciplinar que congrega elementos de diversos campos científicos, como a economia, a ciência política, a sociologia, o direito e demais áreas. Ainda segundo Bursztyn e Bursztyn (2013, p. 145) "políticas públicas são as ações regulares, institucionalizadas, de governos, visando a objetivos e fins determinados".

As políticas públicas estão voltadas para as atitudes tomadas pelo governo gerando um impacto, este é percebido através da ação do governo. Assim Rodrigues (2010) informa que políticas públicas constituem um conjunto articulado de ações, decisões e incentivos que almejam alterar uma situação ou realidade em resposta às demandas e interesses envolvidos. Essas ações são realizadas por pessoas denominadas atores das políticas públicas, essas lidam com algum problema público e são desenvolvidas por instituições públicas governamentais através de um processo político que as condicionam. Deve-se assegurar que o trabalho e o desempenho dessas instituições estejam sempre a serviço do interesse público e submetido ao controle democrático.

Esta definição destaca à ideia de que a Política Pública envolve mais do que uma decisão e requer diversas ações estratégicas selecionadas para implementar as decisões tomadas. Afeta toda uma cadeia, todas as pessoas, independente de quaisquer características a ser analisada e exposta.

Não se faz políticas públicas sem a colaboração da sociedade civil e de todos que compartilham da mesma ideia e buscam o mesmo objetivo. Belinovski (2011) acrescenta que políticas públicas é um conjunto de ações realizadas através de um processo, envolvendo os seguintes atores: a administração pública, os indivíduos e a sociedade civil, onde mediante normas estabelecidas permita alcançar os objetivos traçados de forma prioritária pela coletividade.

“O artigo 174 da Constituição Federal de 1988, apresenta o termo "políticas públicas” como: processo ou conjunto de processos que culmina na escolha racional e coletiva de prioridades, para a definição dos interesses públicos reconhecidos pelo direito"(BRASIL A, 
1988 apud BELINOVSKI, 2011, p.18).Rua (2009) destaca ainda que as políticas públicas são processos resultantes da atividade política, tendo como foco a resolução de conflitos de forma pacífica, pois este processo torna-se necessário e essencial para que ocorra a preservação da vida em sociedade.

Damasceno (2012) converge com o conceito de Belinovski e complementa política pública dizendo que pode ser definida como o conjunto de ações desencadeadas pelo estado com o objetivo de atender à solicitação, necessidade ou demanda de uma sociedade civil, tais ações podem ser desenvolvidas mediante parcerias com organizações não governamentais como também através da iniciativa privada.

Conjunto de medidas e programas governamentais que tem por objetivo influenciar a resolução de problemas do presente em diferentes níveis de escalas (municipal, estadual, federal, nacional ou internacional) objetivando a construção intencional e compartilhada do futuro de uma comunidade, nação ou sociedade. As políticas públicas podem se referir as questões ambientais, socioambientais, sociais, políticas e jurídicas (TASSARA e TASSARA, 2008 apud BIASOLI, 2015, p.51).

Bursztyn e Rodrigues Filho (2016) acrescenta que uma política pública que trate da questão climática deve incorporar políticas ambientais, econômicas e sociais. Especificamente sobre política pública na esfera do tema sobre energia solar, Silva (2015) afirma que as políticas públicas tornam-se de suma importância para crescimento e desenvolvimento de pessoas, localidade, sociedade, país e meio ambiente por diversas razões, dentre tantas tem-se que o Brasil é um país com forte potencial para desenvolvimento da energia solar, estando acima de outras nações quando comparadas com aquelas que já utilizam essa fonte.

O autor ainda comenta que é preciso trabalhar os incentivos, ou seja, o governo, o estado e o município em resumo a administração pública, tem de passar a fomentar, incentivar de forma mais intensa os diversos meios e formas para implantação e a implementação da energia solar nas residências, nos estabelecimentos públicos ou privados, pois os incentivos para a energia solar existentes no País são insuficientes para o indivíduo ou representante de uma empresa decidir trabalhar a sustentabilidade por meio desta, tornando-a insuficiente a sua viabilidade. $\mathrm{O}$ autor enfatiza também que o problema é inviabilidade econômica, para a microgeração e a mini geração distribuídas, nesse caso o investimento inicial é um problema, obstáculo, principalmente quando planeja-se desenvolver a energia solar em residências. 
Ainda Segundo Silva (2015) apesar de serem observadas oportunidades, há a presença de obstáculos institucionais e tributários para que essa fonte de energia seja desenvolvida. Por isso, algumas medidas de incentivo e sugestões de políticas públicas são importantes e devem ser divulgadas. Essas sugestões de políticas públicas inclusive é um dos objetivos específicos deste trabalho.

\section{Metodologia}

Para atender os objetivos descritos na pesquisa foram adotados os seguintes procedimentos metodológicos:

Foi realizado inicialmente uma pesquisa bibliográfica com base em livros, artigos e sites científicos relacionados a políticas públicas para micro e minigeração de energia solar no estado do Ceará: um estudo levando-se em consideração o contexto nacional e municípios no semiárido cearense. Posteriormente realizou-se um levantamento de dados primários com o interesse de entender este cenário não somente na teoria mais compreender o seu formato na vida prática do empreendimento que instalou a energia solar, como investigar o posicionamento dos representantes da administração pública e privada frente ao tema do trabalho e estudo.

A pesquisa está classificada como de natureza básica, pois "é aquela sem finalidades imediatas e que o conhecimento gerado por ela vai ser utilizado em pesquisas aplicadas ou tecnológicas" (PEREIRA, 2012, p.90).

Frente aos objetivos foi exploratória e descritiva (CERVO, BERVIAN,2002). Teve-se o propósito de trabalhar com a abordagem qualitativa. A pesquisa qualitativa é, às vezes, superior no processo de identificação de problemas que em muitas situações passam despercebidas quando se tem um estudo com abordagem quantitativa, assim os sujeitos participantes da pesquisa qualitativa sentem-se mais à vontade para responder aos questionamentos como para dizer ao pesquisador o que lhes interessa (MC DANIEL, GATES,2004). A abordagem mais utilizada em estudos voltados para a área de sustentabilidade, publicados especificamente pelos principais periódicos no Brasil são qualitativos (SOUZA, RIBEIRO,2013). O procedimento técnico utilizado foi o estudo de campo (MARCONI, LAKATOS, 2010). 
O estudo foi realizado em alguns municípios do Semiárido Cearense, sendo eles Juazeiro do Norte, Acopiara, Altaneira, Farias Brito, Jardim, Missão Velha e Várzea Alegre, no período de 01 a 30 de agosto de 2017. Procurou-se em específico incluir e desenvolver o estudo na cidade de Juazeiro do Norte - CE, porque este município apresenta uma população estimada em 270.383, estando-se localizada na região metropolitana do Cariri, ao sul do estado do Ceará, segundo dados do Instituto Brasileiro de Geografia e Estatística (IBGE, 2017). Procurou-se desenvolver também o estudo nesta localidade, pelo fato de ter nesta cidade um exemplo de empreendimento em projeto de energia solar atuante e expressivo, uma Instituição de Ensino Superior (IES) privada que possui mais de 800 placas instaladas e também pela importância de coletar dados dos gestores públicos e privados.

Os sujeitos da pesquisa foram 12 atores públicos e privados ligados ao assunto energia solar, ou seja, com 07 gestores públicos, ou representante da administração pública, 04 gestores de empresa privada de instalação de placas fotovoltaicas, um gestor de empresa privada, cliente de empresa de instalação de placas solares.

O local e sujeitos da pesquisa foram selecionados por conveniência e acessibilidade (MALHOTRA, 2005) e se caracterizassem como empreendimentos ou gestores/representantes de empresas públicas e privadas ligados ao assunto energia solar. No que se refere ao processo de exclusão os sujeitos passariam a ser excluídos do estudo se os pesquisadores não conseguissem realizar a coleta de dados com um dos sujeitos citados anteriormente, vale ressaltar que os clientes residenciais foram excluídos da pesquisa, constituindo-se oportunidade de ampliação do trabalho em momentos futuros.

Para coletar os dados foi escolhido à entrevista como instrumento de coleta de dados. A entrevista é uma "técnica de coleta de informações sobre um determinado assunto, diretamente solicitadas aos sujeitos pesquisados. Trata-se, portanto, de uma interação entre pesquisador e pesquisado. O pesquisador visa apreender o que os sujeitos pensam, sabem, representam, fazem e argumentam" (SEVERINO, 2016, p.133). Foram utilizadas entrevistas semiestruturadas (LAVILLE, DIONNE, 1999, MARCONI, LAKATOS,2010).

As entrevistas foram realizadas de forma individual, pois precisava que os participantes se sentissem à vontade para falar livremente favorecendo a atmosfera informal. As falas dos mesmos foram sumarizadas em subcategorias objetivando facilitar a análise dos resultados. Foi utilizado um roteiro de 06 perguntas para nortear toda a entrevista. 
Quanto à coleta dos dados ou fontes de dados para toda a pesquisa do artigo científico se utilizou de dados primários e secundários (MATTAR, 2005).

A análise dos dados da presente pesquisa foi feita adotando-se a técnica de análise de conteúdo, que segundo Silva e Fossá (2013) é uma modalidade de apresentação de resultados de pesquisas qualitativas.

\begin{abstract}
A análise de conteúdo é uma técnica de análise das comunicações, que irá analisar o que foi dito nas entrevistas ou observado pelo pesquisador. Na análise do material, busca-se classificá-los em temas ou categorias que auxiliam na compreensão do que está por trás dos discursos. $\mathrm{O}$ caminho percorrido pela análise de conteúdo, ao longo dos anos, perpassa diversas fontes de dados, como: notícias de jornais, discursos políticos, cartas, anúncios publicitários, relatórios oficiais, entrevistas, vídeos, filmes, fotografias, revistas, relatos autobiográficos, entre outros (SILVA, FOSSÁ, 2013, p.2).
\end{abstract}

Foram destacadas e consideradas neste trabalho seis categorias-síntese, que serão apresentadas na análise e discussão dos dados.

\title{
Análise e Discussão dos Dados
}

Os dados foram analisados considerando as seis categorias-sínteses, as quais foram assim nomeadas:

1. Importância e vantagens da tecnologia de energia solar no Estado do Ceará e no Brasil;

2. Conhecimento sobre políticas públicas voltadas para a energia solar nas esferas federal, estadual e municipal e delineamento das mesmas;

3. Potencial de crescimento da micro e minigeração de energia solar no Estado do Ceará;

4. Sugestões de políticas públicas que poderiam ser indicadas nas esferas federal, estadual e municipal;

5. Atualmente o que dificulta o desenvolvimento da energia solar no Brasil;

6. Produção atual de Energia Solar para micro e minigeração de energia no Estado do Ceará.

A seguir estão dispostos os resultados e as análises obtidas através da realização das entrevistas com: 07 gestores públicos, ou representante da administração pública; 04 gestores de empresa privada de instalação de placas fotovoltaicas; e 01gestor de empresa privada, cliente de empresa de instalação de placas solares. 


\title{
Categoria 1: Importância e vantagens da tecnologia de energia solar no Estado do Ceará e no Brasil
}

\author{
A presente categoria, buscou apresentar o conhecimento dos atores públicos e privados
} de municípios no Semiárido Cearense acerca da importância e vantagens da tecnologia de energia solar no Estado do Ceará e no Brasil.

Uma localização propícia e os aspectos climáticos que caracterizam o território do Ceará promovem um caminho para geração eficiente de energia solar, desta forma se coloca como de tamanha importância na geração de energias renováveis. A vantagem deste tipo de energia é a implantação e preocupação com uma cultura e uma economia de desenvolvimento sustentável, levando em consideração aspectos econômicos, sociais e naturais. Assim, tem-se como vantagens a redução do custo com energia elétrica e a geração para consumo próprio, principalmente uma preocupação ambiental que já é intrínseco ao seu uso (Entrevistado 1).

Nos últimos anos tem se tornado frequente ver no noticiário falando que os níveis dos reservatórios de água estão muito baixos, e que isso pode levar a necessidade de racionamento de energia. Isso se deve ao fato da nossa matriz elétrica ter em sua maior parte o uso de hidrelétricas. A energia solar irá tornar a matriz elétrica mais variada, e a partir do momento que tenhamos uma quantidade expressiva de energia sendo gerada através da energia solar, será possível controlar melhor o nível dos reservatórios e afastar o risco de racionamento (Entrevistado 2).

Nós temos 1 matriz energética interessante que é a hidroelétrica, mas ela já não está sendo mais suficiente, é uma energia relativamente limpa, mas mesmo assim ela tem um impacto com a natureza e meio ambiente, você desequilibra uma região, você está inundando regiões, você está interrompendo rios, estamos gastando bilhões de um dinheiro que o governo poderia tá atuando numa área social ou em outros investimentos, e poderia tá usando esse dinheiro pra fomentar o que cada família ou empresa tivesse a sua usina e o governo não teria manutenção daquela usina principal. E não vai faltar água, porque a usina hidroelétrica quando falta água, pouca chuva você gera menos energia. E na casa de cada um por exemplo, com a energia solar você não tem falta do insumo principal que é o sol. Então eu entendo que a importância, vantagem dessa tecnologia é total, ela só precisa realmente ter uma política. Se a gente olhar pra Alemanha que já prometeu que em 30 anos vai acabar com a sua energia nuclear, está investindo maciçamente na matriz de energia solar e é́lica, novidade elétrica carros elétricos até 2030, então isso precisa começar, isso não é modismo, isso não é fazer bonito, estratégico, isso é necessidade, assim como nós temos que fazer reutilização da água, recursos hídricos, nós temos uma fonte inesgotável de energia que é o sol, que tá nos oferecendo ai, uma grande oportunidade, e a energia solar, pra você vê nós montamos aqui uma primeira etapa com placas de 255 Watt-pico (Wp), o próximo projeto já é com 330 Watt-pico (Wp), produtividade, a tecnologia, ou seja, por uma mesma placa, pro mesmo, por uma mesma área de captação, vamos dizer assim, e pra eficiência um investimento muito próximo, nós vamos ter uma geração muito maior. 30 a 40\%. Na verdade, nós aumentamos as placas e colocamos um sistema chamado de inteligente, heliotrópico, um projeto girassol que, onde a eficiência de geração está aumentando mais de 40\%, isso já são dados que temos comprovados e quais são os ganhos? Eu ia utilizar para tornar a Leão Sampaio, a UNILEÃO autosuficiente eu precisaria de mais 2800 placas, com o novo sistema serão apenas 1574 se eu compro menos placas eu vou utilizar menos recursos da natureza para construção da placa, eu vou utilizar menos área de terreno para a implantação dessas placas, eu estou utilizando de forma, eu estou recebendo sol e estou transformando mais quilowatts hora né, por unidade de placa, ou por unidade de área, ou por unidade de investimento. Então acho que nós estamos no caminho certo (Entrevistado 3).

Vejo como essencial nos dias atuais a geração de energia limpa, que não agrida a natureza, sem poluição, sem desmatamento, sem barramento de rios e por aí vai desenvolver um modelo de gestão nessa área para torna-la mais acessivel a todos. (Entrevistado 4).

É uma fonte de grande importância e gigantesco potencial, porém ainda pouco explorado diante do leque de oportunidades. Temos regiões com alto índice de luminosidade com gigantescas áreas não agricultáveis ou exploráveis diretamente por escassez de recursos hídricos que poderiam ser utilizadas para implantação desses 
painéis, criando miniusinas em diversos municípios principalmente na região nordeste. Em relação a vantagens, estamos falando de fontes de energia limpa, sem impacto direto ao meio ambiente, de médio custo e retorno a médio prazo, que ao passar do tempo se torna um fator gerador de renda, proporcionando bem-estar às comunidades envolvidas (Entrevistado 5).

Como uma das principais vantagens da utilização da energia solar podemos citar a questão da poluição, já que a energia solar não polui durante o seu uso, outro ponto positivo seria devido ao fato que em países de clima tropical, como o Brasil, o uso da energia solar é viável em praticamente todo o território, e, em locais longe dos centros de produção energética sua utilização ajuda a diminuir a procura energética nestes e consequentemente a perda de energia que ocorreria na transmissão (Entrevistado 6).

A importância é porque é uma fonte de energia limpa. A vantagem é que no Brasil o sol brilha quase o ano inteiro, especialmente no Ceará (Entrevistado 7).

Uma das vantagens é ser uma energia renovável e que não polui, o custo benefício vem a longo prazo. O sol é uma fonte de energia praticamente constante na nossa região, o que torna favorável a implantação e uso (Entrevistado 8).

Do ponto de vista do consumidor a principal vantagem é a redução direta nos seus custos com energia.

Quanto às vantagens intrínsecas à tecnologia, cabe ressaltar a confiabilidade e previsibilidade da produção de energia, uma vez que é possível realizar modelagene e estimar com boa precisão a quantidade da incidência solar, bem como sua posição ao longo dos dias.

Os painéis fotovoltaicos possuem grau de confiabilidade elevado e conseguem manter sua produção mesmo com altas temperaturas que temos no Nordeste.

As centrais em geral são fixas, e, portanto, não têm a presença de componentes móveis, reduzindo os desgastes ao longo dos anos, bem como reduzindo a manutenção. (OBS: existem centrais com trackers que acompanham o movimento do sol ao longo dos dias, mas não são viáveis a longo prazo para pequenos consumidores)

Para a matriz energética nacional, a introdução de novas fontes alternativas de energia, seja a solar, eólica, biomassa, etc, se traduz numa menor dependência da exclusividade das fontes hidrelétricas, o que acarreta uma menor exposição aos fatores hidrológicos (de menor previsibilidade). Assim, caso a tecnologia de fato se expanda a níveis relevantes pode-se inferir que ficaremos menos expostos a eventos como o "apagão" do início dos anos 2000 oи a implantação das bandeiras tarifárias (verde, amarela e vermelha), que elevam sobremaneira os custos com energia.

Além de tudo a energia solar fotovoltaica é de fonte totalmente renovável, que reduz a produção de termoelétricas, por exemplo, que lançam CO2 e outros gases que provocam o efeito estufa na atmosfera (Entrevistado 9).

Redução de investimentos públicos em novas linhas de transmissão; Redução de energia gerada por fontes poluentes (termelétricas); Economia de água dos reservatórios das hidrelétricas; Segurança energética; Eficiência energética; Redução de custos e competitividade (Entrevistado 10).

Então aí a gente vai adentrar agora na questão das vantagens da Energia Solar no Brasil. Uma das vantagens não só para o Brasil, mas para todos os países que adotam esse sistema, é a questão de ser uma fonte renovável e aí a gente entra naquela ideia de na natureza nada se perde, nada se ganha, apenas se transforma, então é uma forma renovável, é uma forma sustentável de se produzir energia e uma energia que a natureza doa para gente, então o que é que o ser o humano tem a ganhar com isso? o que a sociedade tem a ganhar com isso? Consequentemente menores impactos ambientais, porque? Porque é uma energia que está sendo dada pela natureza através do calor solar e é uma energia que vai ser reaproveitada, nós temos indústrias que pagam muito dinheiro em energia, o próprio estado, as próprias instituições que geram energia, as empresas que controlam o setor de energia, elas são empresas que a energia ela é fornecida através da água, da força da água, então nós temos represas que drenam essa água ou que a partir da força dessa água geram energia, então o estado, essas empresas, essas instituições, essas autarquias elas tem muito gasto com isso, e pior, elas muitas vezes nessas implantações possuem impacto ambiental terrível, então uma das principais vantagens para a sociedade para a natureza é a questão de ser uma fonte renovável.

Outra vantagem que a gente pode levantar também, é a questão de não possuir nenhum tipo de adaptação, ou seja, as pessoas para elas se acostumarem com certas coisas elas precisam se adaptar, a energia solar não, porquê? Porque a gente já recebe esse calor do sol, são equipamentos que eles, por exemplo nas casas eles ficam 
no teto, então não tem um processo rebuscado de adaptação para esse sistema, porque? Porque é um sistema voltado para captação solar, é outra vantagem.

A questão da disponibilidade gratuita dessa fonte, então nós temos uma fonte geradora de energia que ela é totalmente gratuita, você não paga para ter luz solar, então é outra vantagem que esse sistema traz, ou seja, uma vez gastado na implementação desse sistema, nós não vamos ter vamos se dizer assim gastos com a fonte de energia que é a solar, porque? Porque mais uma vez ela é uma doação da natureza, o calor solar é uma doação da natureza, então nós, outra vantagem é nós não termos essa questão de vamos se dizer assim de pagamento dessa fonte. Certo?

Outra questão que eu já falei também é uma fonte renovável, é uma fonte sustentável, e é uma fonte limpa, os raios solares eles são fontes puras, são fontes limpas, então é outra vantagem que esse sistema tem, além de outras vantagens financeiras no decorrer dos tempos, enfim, mas as vantagens principais são essas, a questão é uma fonte gratuita, todo mundo dependendo da sua região porque tem região mais fria, região mais quente pode utilizar dessa fonte, é uma fonte gratuita, e é uma fonte renovável você está pegando aquilo que é dado pela natureza e está contribuindo com a natureza.

E eu vou citar para diferenciar um pouco a questão também das desvantagens, já que a gente está falando das vantagens, uma desvantagem como eu já tinha falado é um custo acentuado, hoje nós não temos para implantar um sistema desse um custo acessivel a todos, ou a todos os seres humanos, porque? A gente tem pessoas de baixa renda que não tem condições, essa prática de implementação desse sistema solar está sendo muito utilizada em empresas, em instituições como a Leão Sampaio, a Unileão que consome muita energia e consequentemente paga muito caro por ela, então eles precisam investir, esse custo não é um custo acentuado, porque? porque eles precisam ter uma redução do consumo de energia, vai ter uma interligação desse sistema solar com a rede elétrica, nós temos até informativos que diz que, caso essa energia não seja consumida, por exemplo você capta essa energia solar, ela vai para a rede elétrica dessa instituição dessa empresa, caso ela não seja consumida totalmente naquela empresa, naquela repartição, naquele empreendimento, ela é voltada, ela retorna para a rede elétrica do município, então é uma vantagem assim estupenda, mas tem essa questão do custo acentuado que ainda se torna um entrave, ainda se torna uma dificuldade muito grande.

Outra dificuldade também é a questão da própria dependência climática, como eu já falei, tem estados que infelizmente não tem muita aceitação para implementação desse sistema, porque? Porque um estado que ele tem muita incidência de chuva, de nevoeiros, certo? O clima é um clima mais frio, ou seja, mais elevado, esses sistemas praticamente não vigoram, porque não recebem muito a luz solar, e a questão das próprias placas que recebem, essas placas solares, elas têm uma grande demanda de extração de minérios, e minérios além de serem raros, muitas vezes são caros. Então esse sistema eu diria que ele tem mais vantagens do que desvantagens em si próprio, mas acredito e a gente tem uma grande possibilidade de acordo com os estudos que são desenvolvidos e publicados que serão tendências futuras, serão tendências futuras. (Entrevistado 11).

Tornar a matriz energética do país mais diversificada, explorar uma fonte de energia renovável e economicamente promissora, criar novos empregos, aumentar a produção industrial e etc (Entrevistado 12).

Os resultados mostrados anteriormente confirmam informações apresentadas por Carvalho e Calvette (2010), Governo do Estado do Ceará (2011), Georgescu - Roegen (2012, p. 120), Knob (2013), Torres (2012), Castelli (2015), IBGE (2015), Silva (2015), e Bursztyn e Rodrigues Filho (2016). 


\title{
Categoria 2: Conhecimento sobre políticas públicas para a energia solar nas esferas federal, estadual e municipal e delineamento das mesmas
}

\author{
A presente categoria, retrata especificamente o conhecimento por parte dos
} entrevistados sobre políticas públicas voltadas para a energia solar nas esferas federal, estadual e municipal. Os entrevistados mostraram conhecimento parcial das políticas públicas e alguns deles não tem nenhum conhecimento sobre as políticas públicas ligadas a temática, constituindo uma oportunidade de melhoria.

O Estado do Ceará apresentou uma lei que garante a isenção do Imposto de Circulação de Mercadorias e Serviços (ICMS) para microgeração de energia, garantindo a construção de uma usina na cidade de Pindoretama, esta iniciativa poderá facilitar o desenvolvimento de políticas públicas a nível municipal. A Agencia Nacional de Energia Elétrica (ANEEL), estabeleceu regras para a micro (até $100 \mathrm{~kW}$ ) e a mini geração (entre $100 \mathrm{~kW} \mathrm{e} 1.000$ $\mathrm{kW}$ ) que permitiu que consumidores gerem sua energia e troquem o excedente por créditos provocando o desconto em futuras contas de luz (Entrevistado 1).

O primeiro incentivo que tivemos foi a possibilidade da instalação de sistemas fotovoltaicos conectados à rede pois antes da publicação da resolução normativa 482/2012 da ANEEL era impossível ter esse tipo de tecnologia instalada e conectada à rede da distribuidora de energia local. Por mais absurdo que seja alguns estados cobram ICMS sobre a energia produzida e injetada na rede. Aqui no Ceará e 20 estados já aderiram ao convênio CONFAZ que elimina essa cobrança (Entrevistado 2).

É uma iniciativa nova, e eu não conheço todas elas mas, o que a gente sabe é que existe financiamento com juros baixos, pra incentivar tanto ao setor público quanto o privado, em todos os níveis, seja o micro, o pequeno, médio e o grande empresário, onde os empresários menores, de menor porte tem o juro mais baixo, e você tem inclusive carência pra iniciar os pagamentos, então se o juro é baixo, se o dinheiro não vai ter grandes dificuldades pra sair e se o retorno do investimento hoje vai oscilar entre 4 e 7 anos para um aparato pra um equipamento que tem na sua maioria uma garantia de 25 anos, vamos dizer que temos quase 20 anos de geração de energia, essas pessoas estarão comprando uma usina de energia pra terem um benefício já depois de pago, por quase 20 anos, e se podemos falar de uma certeza no Estado do Ceará, tem muitas incertezas mas uma grande certeza é o sol (Entrevistado 3).

Não conheço, porém, gostaria que as políticas públicas se voltasse para as instituições, órgãos e entidades, utilizando essa tecnologia nas escolas, secretarias, hospitais, postos de saúde, praças e outros (Entrevistado 4).

A nível estadual, segundo dados do IBGE em 2015, o Estado do Ceará responde sozinho por 67,24\% do total da potência solar outorgada no Brasil. De acordo com estes dados, o Ceará possui o projeto de geração distribuída industrial de energia solar do país. Trata-se da Usina do grupo Telles, localizada em Pindoretama, na região metropolitana de Fortaleza (RMF), se configurando no maior do país. No Estado do Ceará, a COOPERFANCooperativa Agroecológica da Agricultura Familiar do Caminho de Assis-entrou como a primeira cooperativa a instalar um equipamento para captação de energia solar. A cooperativa efetuou todo o projeto com financiamento público, através de linhas de financiamento pelo governo estadual.

Nessa primeira você pode colocar essa cooperativa como exemplo de resultado de política pública para desenvolvimento de energia solar no Ceará, já que o governo estadual disponibiliza recursos para desenvolvimento de projetos na área (Entrevistado 6).

Ouvir falar. Alguns projetos iniciados nos institutos tecnológicos no estado do Ceará, em algumas universidades de tecnologia. Porém o pouco que ouvi ainda se trata de projetos experimentais (Entrevistado 7).

Sim, existem algumas políticas públicas interessantes voltadas para a energia solar, uma delas é a isenção de ICMS para a geração de energia, que já é adotada em 24 Estados (Entrevistado 9). 
Programa Luz Para Todos, a Coelce instalou 73 unidades residenciais no interior do Ceará com 3 (três) módulos solares fotovoltaicos de 260Wp cada e 6 (seis) baterias geoestacionárias. Suficiente para um consumo de até $120 \mathrm{kWh} / \mathrm{mês}$. O recurso é proveniente do Governo Federal (Entrevistado 10).

E no Ceará em relação a políticas públicas voltadas para essa área, o governador do estado, Camilo Santana em relação a esses microgeradores de energia solar, ele mandou para a Assembleia legislativa um PL que é um Projeto de Lei que isenta as empresas de pagar o ICMS, as empresas que possuem esses sistemas. Porque? Como eu estava falando o Marcelo Alexandrino que é um doutrinador de direito constitucional ele diz que como eu já tinha falado, que não basta só o país produzir, que não basta só o estado produzir, de forma desenfreada, mesmo que essa distribuição de renda seja equânime. A gente sabe que a distribuição de renda no Brasil ela é muito desproporcional, a gente tem poucos ricos e muitos pobres e os estados por si só eles são muitos desiguais, então mesmo que o país produza, que acumule riqueza de forma igual, igualitária, equânime, mesmo que ele faça isso, mas não se atente para essas questões ambientais, é sustentativo só em frutíferas, porque? Porque mesmo tendo está distribuição igual, o país, o estado vai sofrer os impactos ambientais lá na frente e vão ser muito mais caros do que essa própria igualdade da ordem econômica. E aí esse doutrinador ele diz que é extremamente importante e viável aquela empresa que menos impactar o meio ambiente, aquela empresa que mais desenvolver ações, projetos, para que seja reduzido impactos ambientais essa empresa ela deve ter, vamos dizer assim uma premiação, ela deve ter um reconhecimento do estado, seja na redução de ICMS, seja na redução de IPTU no caso dos municípios, em fim na redução de alguma taxa, de algum imposto, de algum tributo que essas empresas pagam ao estado. Então é uma forma do estado a cada dia como eu já falei que essa é uma das dificuldades, estimular, do estado apoiar, e do estado investir nesse setor, não só da energia solar, como da energia eólica e outras fontes renováveis e outras fontes sustentáveis que o Estado do Ceara tem potencialidade, então o governo do estado ele deu esse grande avanço em relação a essa questão da energia solar, uma energia renovável, de fonte renovável muito utilizada também é a eólica, porque? Porque nós temos a parte litoral, a parte litorânea das praias, e o estado ele possui uma grande potencialidade na questão da energia eólica, que é a energia que é gerada por meio do vento, certo? Então essas duas questões a questão do setor privado, do estatal que hoje o estado possui empresa que ela é reconhecida mundialmente por ter essa implantação desses micro e mini geradores de energia solar e do setor privado e o estado em começar em iniciar a desenvolver ações que incentivem essas práticas. Já pensou se cada repartição pública do estado não tivesse mais sendo utilizada a energia elétrica? E sim a energia solar? O quão grande era o benefício para o meio ambiente, para os cofres públicos, e para o andamento da administração pública? (Entrevistado 11).

Apenas a isenção do ICMS (em todo território do pais) na compra de kits de energia solar fotovoltaicas e na geração ligada à rede, (apenas em alguns estados como, por exemplo, o Ceará também existe a isenção do ICMS sob a geração) (Entrevistado 12).

Os entrevistados mostraram conhecimento parcial das políticas públicas e alguns deles não tem nenhum conhecimento sobre as políticas públicas ligadas a temática, constituindo uma oportunidade de melhoria.

Os resultados mostrados anteriormente confirmam informações apresentadas por Carvalho e Calvette (2010), Georgescu - Roegen (2012, p. 120), Knob (2013), Torres (2012) e IBGE (2015). Brasil A, (1988 apud Belinovski, 2011, p.18), Rua (2009), Rodrigues (2010), Belinovski (2011), Damasceno (2012), ANEEL (2012, 2014 e 2016), Bursztyn e Bursztyn (2013), Bursztyn e Bursztyn (2013, p. 145), Tassara e Tassara (2008 apud Biasoli, 2015, p.51), Brasil B (2015), IBGE (2015), Silva (2015), Neto, Madruga e Geremias (2016), Bursztyn e Rodrigues Filho (2016). 


\title{
Categoria 3: Potencial de crescimento da micro e minigeração de energia solar no Estado do Ceará
}

\author{
A presente categoria, tratou de apresentar o conhecimento por parte dos entrevistados
} acerca do potencial de crescimento da micro e minigeração de Energia Solar no Estado do Ceará.

O Estado do Ceará possui um grande potencial na geração de energias renováveis, entre elas a solar. O território possui uma grande vocação nesta produção, pois devido aos seus aspectos climáticos ocorre uma elevada incidência no índice de insolação durante boa parte do ano, condições estas que garantem eficiência e estabilidade na geração de energia advinda desta fonte, o que leva a um elevado potencial de produção colocando-se em destaque nacional, assim, a adoção de políticas públicas na área elevaria ainda mais o crescimento do Estado (Entrevistado 1).

O potencial de crescimento em todo o Brasil é enorme. Se formos analisar a nossa região, o Cariri, podemos observar que a quantidade de instalações desse tipo é mínima. Considerando as cidades de Crato, Juazeiro do Norte e Barbalha não temos nem 30 instalações. As pessoas estão começando a abrir os olhos e aos poucos vendo que esse investimento vale a pena (Entrevistado 2).

Nós estamos numa região de, umas das melhores incidências solares do mundo, tanto solar como de vento pra o eólico, e isso tem que ser aproveitado, porque é o investimento que você vai fazer para algumas décadas, é energia limpa, é uma energia barata, com retorno de investimento relativamente, curto, eu estou falando de 4 a 7 anos, isso passa muito rápido, então a mini e microgeração ela tem tudo para dar certo, é, ou você incentivando cada família, ou você indo pelas construtoras dando um desconto no alvará, no habites, você tem ferramentas, o selo verde é uma coisa ainda não muito divulgada, exercitada, mas é uma ideia interessante também, você cria créditos pra você se beneficiar em várias operações financeiras, se você é um investidor em sustentabilidade. Eu não consigo obter vendas de crédito de carbono aqui, ainda não, mas é possível, é que eu não fui atrás, mas existe, já existe (Entrevistado 3).

O Ceará tem sol 9 meses por ano, porém ainda pouco aproveitado (Entrevistado 4).

Gigantesco, pois nosso estado se situa em uma das regiões com maior índice de radiação solar, com dias longos e número de horas do dia bem acima do restante do país. Temos áreas enormes para implantação de painéis, muita mão-de-obra que ainda pode ser explorada nessa atividade, mas infelizmente ainda não há investimentos visíveis no setor pelo governo federal (Entrevistado 5).

Pelas condições climáticas e geográficas tão favoráveis ao desenvolvimento da energia solar: a proximidade à linha do equador e com incidência de raios solares regulares, o Ceará detém um excelente potencial para o crescimento da energia solar (Entrevistado 6).

Muito alto (Entrevistado 7).

Grande possibilidade de crescimento, pois temos a fonte solar privilegiada praticamente o ano inteiro, porém não existem investimentos, e se trata de um custo muito alto (Entrevistado 8).

Alto potencial de crescimento, uma vez que o Ceará é um estado geograficamente bem localizado, e possui tarifa de energia relativamente mais alta que os estados circunvizinhos, como RN e PI (Entrevistado 9).

Devido a sua localização, próximo à linha do Equador, com excelentes índices solarimétricos e devido boa incidência de ventos que "esfriam" os painéis solares fotovoltaicos e que também ajuda no seu desempenho, sem dúvida a mini e microgeração é um caminho sem volta no Estado do Ceará. É um mercado que permanecerá forte em pelo menos nos próximos dez anos (Entrevistado 10). 
O Estado do Ceará por fazer parte de uma região Nordeste, tem um potencial altamente apto para implantação desse sistema. E os estados em si eles, a maioria deles eles estão começando a fazer estudos para que esses sistemas sejam implantados, e aí nós poderemos já que a pergunta é voltada para o Estado do Ceará, a gente pode citar um exemplo, a maior usina de energia solar privada do país, ou seja, a maior usina de energia solar de caráter privado do país está no Estado do Ceara, então isso é um grande passo, basicamente na região metropolitana de Fortaleza, e ela é conhecida como grupo Telles que é interligada a outras empresas, certo? e ai esse grupo decidiu investir enquanto instituição privada, e aqui nós não estamos falando em instituição pública, em repartição pública e sim repartição privada, mas só citando o exemplo de como isso está sendo encarado no Estado do Ceará, então nós temos essa empresa que hoje ela é referência, infelizmente essa microgeração distribuída de energia é para o consumo da própria empresa, essa empresa ela poderia já que ela investiu mais de 30 milhões nesse investimento ela poderia muito bem vender esta energia, ou comercializar em fim mas essa energia ela é voltada para o próprio consumo da empresa, então é uma empresa hoje no Ceará e no Brasil reconhecida por ter esse potencial, por aderir a essa prática, e ela tinha uma taxa mensal de pagamento de energia segundos dados informativos do site da própria empresa que divulga essa questão essa implantação essa microgeração distribuída de 300 mil reais por mês. Então você imagina uma empresa todo mês pagar 300 mil de consumo de energia? Então no momento esses 30 milhões que foram gastos com a implantação desse sistema segundo dados informativos da própria empresa nos sites e aí se você pesquisar você vai encontrar, mas que é um gasto que essa empresa poderá a não ter mais com este consumo de energia durante muitos anos e aí 20 milhões desse investimento são só na questão dos equipamentos, que muitas vezes precisam vir dos Estados Unidos, e de outros países de tecnologia de ponta. Então é um grande avanço (Entrevistado 11).

Não só no Ceará, mas, vejo em todo o território nacional, uma grande possibilidade de crescimento do mercado solar, visto que, pela primeira vez está claro que o sistema de geração das hidroelétricas está verdadeiramente sobrecarregado; devido as secas prolongadas em todo o pais as mesma estão a muitos anos sem atingir suas capacidades máximas e não só por questões ambientais mas, por questões de mercado; investir em novas fontes de energia é algo emergencial e nada melhor do que o próprio consumidor residencial produzir sua própria energia, tirando assim um "grande peso" do sistema de distribuição e possibilitando as grandes geradoras focarem na indústria e nos grandes consumidores. Então, mesmo o mercado solar começando a aquecer de forma tardia em nossos pais, mas, por ser uma questão de necessidade, traz junto muita abertura para crescimento (Entrevistado 12).

Os resultados mostrados anteriormente confirmam informações apresentadas por Governo do Estado do Ceará (2011), G1 (2011), ANEEL (2012, 2014 e 2016), IBGE (2015), Solarterra apud Picanço (2015), Silva (2015), Ambiente Energia (2016), Jornal o Povo (2016).

\section{Categoria 4: Sugestões de políticas públicas que poderiam ser indicadas nas esferas}

\section{federal, estadual e municipal}

Esta categoria apresenta uma análise por parte dos entrevistados sobre as sugestões de políticas públicas que poderiam ser indicadas nas esferas federal, estadual e municipal.

Criação de um fundo de incentivo à produção de energia solar e outras tipologias renováveis. Linhas de financiamento na aquisição de equipamentos que levem a produção de energia e o uso da mesma. Políticas de incentivos a troca da energia elétrica pela energia solar elou eólica (Entrevistado 1).

Acredito que o principal incentivo que devemos ter é a criação de linhas de crédito acessível. A melhor taxa que temos no mercado hoje para PF fica na faixa de 2,2\% a.m. com prazo máximo de 36 meses. Isso acaba dificultado a aquisição dos equipamentos. Há um projeto de lei em andamento que prevê o uso do FGTS dos trabalhadores 
para aquisição de sistemas fotovoltaicos e aquecedor solar, com a aprovação desse projeto iria beneficiar muitos trabalhadores.

A nível municipal temos um problema que é a taxa de iluminação pública, pois ela é calculada sobre o consumo de energia. Nesse caso mesmo que o consumidor produza toda a sua energia, ele ainda pagará uma taxa alta referente a iluminação pública. Também acredito que essa alteração no cálculo seja importante para incentivar ainda mais a adesão aos sistemas de energia solar.

Como sugestão podemos aproveitar ideias de outros municípios que já dão desconto no IPTU de residências com sistemas de energia solar instalado, e também acredito que todos os órgãos das três esferas do governo deviam adquiri esse tipo de sistema para instalação nos prédios públicos, dessa forma irá difundir a tecnologia e incentivar a aquisição por um número maior de pessoas (Entrevistado 2).

Existe uma restrição hoje que equipamento importado não tem financiamento. Eu entendo que numa arena de globalização você criar uma restrição, ou uma proteção a importação sendo que o produto de fora ainda tem uma qualidade superior e o preço menor, porque eles tem escala, mas eu sei que no Brasil nós já temos 2 ou 3 empresas se desenvolvendo, elas não tem ainda preço competitivo, apesar de ter boa qualidade porque não tem escala, então é uma questão de tempo, a questão de quem vem primeiro o ovo ou a galinha, precisa ter escala para baixar o preço, precisa baixar o preço pra ter escala. O financiamento só é com equipamento nacional. O equipamento para você, que você importa você não consegue ter o financiamento. Já tem gente produzindo. Já tem gente da própria Caneidia que é o que a gente reconhece hoje como um dos melhores, produzindo aqui no Brasil, montando empresa no Brasil, em Campinas, não sei se eles vão mandar componentes aqui para o Brasil, vão montar ou se vão produzir a partir do zero né, da matéria prima, mas eu entendo que o financiamento seria uma $1^{a}$ iniciativa, pública para fomentar isso. A $2^{a}$ coisa que poderíamos, eu entendo que se houvesse uma grande divulgação, mostrar para as pessoas que o próprio governo podia bancar esse investimento e depois ir tendo um desconto na conta de energia. Hoje nós já fizemos algumas contas, as pessoas poderiam pagar pela usina de geração, o mesmo valor da conta de energia que ele pagava, ou seja, é como você deixar de pagar o aluguel e pagar a prestação da sua casa, depois de um certo tempo você é o dono da casa. Você não está tendo um gasto, uma despesa, você está fazendo um investimento. E essa contribuição do governo viria através por exemplo de abatimento de imposto de renda, acho que existe várias formas, você pode dar um desconto no IPTU, você pode reduzir o Imposto de Renda (IR), ou simplesmente, aí IPTU seria municipal, seria facilitar a comprar, a aquisição por parte das pessoas que nós teríamos, inclusive de baixa renda. Você poderia ter por exemplo as construtoras já gerassem todos os prédios, todas as casas, todos os condomínios com energia solar, inclusive os prédios públicos, principalmente, onde uma das principais despesas dos órgãos públicos é a energia elétrica (Entrevistado 3).

Sugiro a resposta da primeira questão acima (Entrevistado 4).

Formação de consórcios entre as entidades públicas para o desenvolvimento de linhas de crédito diretamente para a microgeração, em especial ao produtor rural, pois esse dispões de grande espaço em suas propriedades $e$ além de abastecimento próprio, essa atividade poderia ser um fator gerador de renda. Também poderia haver implantação de sistemas de energia solar nos órgãos públicos, para dar mais visibilidade a esse tipo de fonte de energia e quem sabe estimular a instalação por outras pessoas (Entrevistado 5).

A principal indicação seria de um maior investimento do poder público no que se refere ao desenvolvimento de energia solar no país, sobretudo no Nordeste. Atualmente, o que vemos é que existe um fomento muito maior nessa área através da iniciativa privada. Acho que ainda falta, pelo poder estatal, um maior interesse em investir na área de pesquisa e desenvolvimento de tecnologia para produção de fontes de energia limpa, como é o caso da energia solar (Entrevistado 6).

Parceria público privada para financiar investimentos na implantação e manutenção de sistemas de produção de energia solar para suprir as necessidades de energéticas dos equipamentos públicos. A crítica que faço é em relação a resistência adotada pelos gestores públicos em implantar esses sistemas (Entrevistado 7).

Incentivos através de emendas ou programas sociais, por meio de consórcios, que facilitasse um maior número de pessoas a possuir. Infelizmente, não tenho conhecimento de nenhuma política sobre esse assunto (Entrevistado 8).

Respondido na questão 1. A ampliação dessas políticas para todos os estados da federação seria de suma importância para a evolução da implementação da tecnologia (Entrevistado 9). 


\section{Federal:}

Desoneração dos impostos federais da cadeia produtiva, pelo menos pelos próximos dez anos;

Fortalecimento e desburocratização das linhas de financiamento FINAME e FNE SOL para compra de geradores solares fotovoltaicos;

Estadual:

Incentivo à produção de energia solar em prédios públicos em geral (escolas públicas, hospitais e administração pública);

Manter o Convênio CONFAZ ICMS 105/97 (desoneração de ICMS) nos componentes de geradores solares fotovoltaicos;

Manter a desoneração de ICMS na energia injetada da rede pelo mini e microprodutor para consumo próprio;

\section{Municipal}

Incentivo à produção de energia solar em prédios públicos municipais em geral;

Incentivo de desoneração parcial de IPTU para imóveis que utilizem energia solar. (Entrevistado 10).

Já foi comentado nas demais perguntas (Entrevistado 11).

O melhor incentivo possível é o investimento financeiro. Acredito que está mais do que na hora de todas as esferas públicas pensarem em uma forma de criar uma linha de credito especifica para pessoas físicas, com baixas taxas de juros, compatíveis com a economia e o tempo de retorno que o cliente teria ao colocar um sistema solar fotovoltaico em sua residência, pois, apesar de bastante viável, o cliente hoje tem que praticamente pagar à vista um sistema que corresponde há quase 6 anos de energia à vista, dependendo do seu sistema.

A crítica que faço é a falta de interesse dos governantes em pensarem em como tornar real a utilização das outras fontes energéticas em nosso país, pois, há muito tempo que os nossos recursos hídricos estão sobrecarregados (Entrevistado 12).

Os resultados mostrados anteriormente confirmam informações apresentadas por Rua (2009), Bursztyn e Bursztyn (2013), Bursztyn e Bursztyn (2013, p. 145), Rodrigues (2010), Belinovski (2011), Brasil A (1988 apud Belinovski, 2011, p.18), Damasceno (2012), Tassara e Tassara (2008 apud Biasoli, 2015, p.51), Bursztyn e Rodrigues Filho (2016) e Silva (2015).

\section{Categoria 5: Atualmente o que dificulta o desenvolvimento da energia solar no Brasil}

A presente categoria, apresenta uma análise sobre o conhecimento dos entrevistados acerta do que atualmente dificulta o desenvolvimento da Energia Solar no Brasil.

A falta de incentivo no financiamento de projetos de eficiência energéticas, seja para uso residencial ou comercial. A elevada carga tributária ainda inserida nestes equipamentos, bem como na energia gerada dificulta o desenvolvimento desta prática positiva na produção de energia renovável (Entrevistado 1).

O primeiro fator é cultural, pois energia solar é um investimento com retorno em 5-7 anos. Quando falamos sobre esse prazo para as pessoas elas acabam achando que é muito tempo, e ignoram que a vida útil dos equipamentos é longa, as placas solares por exemplo têm garantia de 25 anos.

Muitas pessoas ainda não sabem que é possível produzir sua própria energia, então é importante que mídia divulgue essa tecnologia para que as pessoas tenham conhecimento, e busquem se tornar produtores da sua própria energia (Entrevistado 2). 
O investimento ainda é um pouco alto e pegou um momento que as pessoas estão receiosas em fazer investimentos, em função dessa crise política, a crise financeira, eu não gosto de usar a palavra crise, vamos dizer num momento de transformação, e de mudanças de cenário político, econômico e social, mas é na crise que a gente encontra oportunidades. Eu vou repetir, como a energia é um dos maiores gastos das famílias, das empresas, inclusive do setor público, me parece um item prioritário para eu buscar alternativas e ela está aí na nossa conta, não é uma coisa que não é acessível, está a nossa conta (Entrevistado 3).

Sim, começar pelos legisladores que ainda não ver como necessário e eficiente a produção de energia renovável, o estado ainda valoriza muito a geração de energia através da água. Outro ponto, é os preços praticados ainda pelas empresas que fabricam e comercializam os equipamentos, tornando muitas vezes duvidoso o investimento por parte da população (Entrevistado 4).

A falta de mão de obra qualificada, a dificuldade na emissão de licenças ambientais, a ausência ou desconhecimento de linhas de crédito acessíveis a parcela da população que dispõe de menos recurso são, ao meu ver, os principais fatores que dificultam a exploração dessa fonte de energia. E ainda há de forma complementar um custo inicial alto para implantação dos sistemas (Entrevistado 5).

É fato que o preço e a viabilidade de uma dada fonte energética dependem primordialmente da implementação de políticas públicas, de incentivos, de créditos com baixos juros, de redução de impostos. Enfim, de vontade política para fazer acontecer. Por outro lado, também é necessário que se reveja a burocracia existente junto às distribuidoras de energia no país para a utilização de energia solar, afinal são elas que administram todo o processo, desde a análise do projeto inicial de engenharia até a conexão à rede elétrica. Cabe a estas empresas efetuarem a ligação na rede elétrica, depois de um burocrático e longo processo administrativo realizado pelo consumidor junto à companhia. Sendo todo este processo extremamente burocrático e caro, que acaba por desestimulador o interesse pela utilização da energia solar (Entrevistado 6).

Falta de conhecimento, falta de vontade dos gestores, protecionismo de grandes empresas do setor elétrico (Entrevistado 7).

Falta de interesse público para investimentos (Entrevistado 8).

O principal entrave que observo no mercado trata-se do financiamento dos sistemas para Pessoas Físicas, ainda há restrição de crédito e taxas elevadas o que inviabiliza a execução de projetos (Entrevistado 9).

Sim. Limitações nas fontes de financiamento com taxas de juros que permitam um favorável retorno de investimento (payback).

Financiamentos com FNE SOL (BNB) e FINAME (BNDES) são bem atrativos quanto aos juros, mas ainda são extremante burocráticos e demorados (Entrevistado 10).

Bom, primeiramente esse tema é um tema que ele é muito dimensional, ele não é um tema que envolve só a área administrativa, ele envolve vários aspectos em relação a matéria, bom por exemplo: direito ambiental, direito sustentável, envolve física, envolve a parte administrativa, e aí eu como secretário de meio ambiente eu não tenho conhecimento sobre tudo, sobre todos os aspectos em relação a energia solar, porque? Porque esse é um tema ainda muito controvertido, e é um tema entre aspas recente, para questão de adaptação e tudo, e aí, o Brasil ele é privilegiado pela questão da iluminação solar, principalmente na região Nordeste, porque? Porque é uma região muito quente e é uma região que facilmente se adaptaria e servia para a questão da implantação da energia solar. Certo? Porque? Porque o potencial do Nordeste, o potencial brasileiro para implantação desses sistemas é altamente viável, o Brasil ele possui grande potencial nesse sentido, e aí dentre as perguntas que foram elaboradas aqui, tem a questão também principal da contribuição para o meio ambiente, e aí se você for vê alguns doutrinadores eles sempre adentram para essa questão sustentável, porque essa é uma medida sustentável, certo? O Marcelo Alexandrino que trata sobre o direito constitucional brasileiro ele diz que na parte de ordem econômica que não basta só o país crescer, não é interessante que o país só cresça e produza acúmulo de capitais e gere riqueza, porque? Porque se o Brasil só crescer, só se desenvolver nessa ordem econômica e não respeitar os ditames ambientais, não respeitar os ofícios que rege para que a natureza seja preservada, nós iremos comprometer as presentes e as futuras gerações, então lá na frente todo esse acumulo de riqueza, todo esse aparato econômico ele vai ser inútil, porque? Porque nós não temos e não tivemos a preocupação da preservação do meio ambiente, desta própria questão de sustentabilidade, de um desenvolvimento sustentável, que também faz. 
muita referência a esse tema. Então em relação à sua pergunta das dificuldades existentes ao desenvolvimento da Energia Solar no Brasil, nós temos sérias e graves dificuldades, porque? Porque a gente ainda insiste em bater nessa tecla, de que essa forma de se fazer essa energia ela ainda é, vamos se dizer assim, é economicamente inviável, vários gestores, eu até anotei aqui alguns posicionamentos que eu tenho, que alguns gestores insistem como eu já falei em bater nessa tecla de que essa fonte solar, todo esse aparato que traz, que busca essa energia solar é caro. Então muitas vezes nós temos municípios, nós temos estado que estão passando por algumas dificuldades e que é uma solução benéfica para o estado, porque o estado e quando eu falo de estado eu falo em pessoas, elas consomem muita energia e o estado possui um grande gasto de energia, mesmo as empresas que regulamentam essa distribuição de energia, sendo privatizadas, mas quanto não se gasta em cada repartição pública? E o município ele paga por isso, o estado ele paga por isso, a união paga por isso, então uma das dificuldades é a questão da própria viabilidade econômica, que os entes federativos eles têm que investir realmente nesse setor, de transformação da energia solar, da captação da energia solar interligada a energia elétrica, apesar de ter esse potencial, tem-se essa dificuldade na questão da viabilidade econômica, porque? porque muitas vezes nós temos que buscar essas placas, esses materiais de outros países, aqui no Brasil muitas vezes não tem pessoas capacitadas para fazer toda essa interligação, todo esse sistema, então um dos principais problemas e uma das principais dificuldades é a questão da viabilidade econômica, outro ponto fundamental também é a gestão da falta de interesse, da falta de apoio e da falta de estímulo das instituições governamentais, das próprias instituições governamentais, então o governo, as instituições, os entes federativos, as autarquias precisam investir, precisam dialogar mais com esse setor, precisa viabilizar, fazer um planejamento e realmente incentivar essa prática de uso da energia solar, certo? Então apesar do Brasil ser um país potencialmente, principalmente na região Nordeste viável para implantação desses equipamentos, a contribuição solar na matriz elétrica brasileira quase inexiste, então o que é que a gente quer dizer com isso? Que apesar de todo esse potencial, essa implantação da captação de energia solar no Brasil nós temos pouquíssimos exemplos, então quase inexiste, por causa dessa inviabilidade econômica, por causa dessa falta de estímulo, de estudos, de planejamentos, de ações governamentais voltadas para isso, os estados agora que estão começando a discutir e a ver meios para implementar essa questão. Certo? E você poderia pedir um exemplo de como o estado poderia investir ou até vamos se dizer assim estimular, por exemplo, os bancos, os bancos oficializados, o Banco do Brasil é uma empresa pertencente a União, certo? Então o BB enquanto representante, uma instituição da União, uma sociedade de economia mista é, o que é que ela poderia fazer? Poderia dar descontos, por exemplo na taxa dos juros, de alguma empresa, de alguma pessoa física, ou jurídica que implementasse essas ações, o município na questão da redução da taxa de IPTU, ou na redução da própria taxa de iluminação pública, então falta incentivo, falta apoio dessas instituições governamentais, para que esses procedimentos sejam bem desenvolvidos, então aí e o que a gente tem a abordar desse quarto item, certo? (Entrevistado 11).

A falta de investimento em uma produção nacional das placas fotovoltaicas e a falta de linhas de créditos atrativas para o consumidor pessoa físico (Entrevistado 12).

Os resultados obtidos vão de encontro ao pensamento de Silva (2015).

\section{Categoria 6: Produção atual de Energia Solar para micro e minigeração de energia no Estado do Ceará}

Esta categoria, relata o conhecimento dos atores públicos e privados de municípios no Semiárido Cearense acerca da produção atual de Energia Solar para micro e minigeração de energia no Estado do Ceará.

Segundo o IBGE o Estado do Ceará é responsável por 67,24\% do total da potência de energia solar no Brasil, possuindo o maior projeto de geração industrial de energia do país com o Grupo Telles (Entrevistado 1). 
No Ceará temos um total de 428 unidades conectadas à rede da ENEL, com uma potência instalada de 10,122 MWP, a energia produzida é suficiente para atender cerca de 4.900 residências que consomem 300KWh/mês, segundo dados da ANEEL (Entrevistado 2).

De acordo com a associação brasileira de energia solar fotovoltaica, no ano de 2016, a produção de potência distribuída feita pelo consumidor, indústria e comércio teve potência somada de $58 \mathrm{MW}$, equivalentes a 7.600 sistemas instalados (Entrevistado 6).

No ano passado vi notícias de que tem sido feito investimentos por parte de empresários, na produção de energia solar para consumo nos seus empreendimentos. E o governo do estado já mostrou interesse, porém pouco divulgado o assunto (Entrevistado 8).

Atualmente são 472 sistemas conectados no CE, com potência instalada em torno de 20,5 MW (Entrevistado 9).

Percebeu-se que a maioria dos entrevistados não soube passar esta informação, constituindo uma oportunidade de melhoria quando se refere a necessidade de maior disseminação desta tecnologia. Os resultados obtidos vão de encontro ao pensamento do Governo do Estado do Ceará (2011), IBGE (2015) e de Silva (2015).

\section{Considerações Finais}

O presente estudo atingiu seus objetivos, no momento em que se conceitua e se identifica as políticas públicas atuais de incentivo para energia solar existentes no Estado do Ceará e as sugestões e oportunidades para o incremento desta matriz também nas esferas municipal e federal.

Após feita a coleta de dados, apenas uma única hipótese foi validada, refutando as demais. Dessa forma, a hipótese validada foi a última, onde os entrevistados mostraram conhecimento parcial das políticas públicas e apresentaram sugestões.

Diante de todo o cenário apresentado e do potencial que o Brasil e o Ceará têm em relação à energia solar, é possível constatar que o Estado do Ceará está demonstrando ações de incentivo a esta matriz energética e os números começam a justificar que as políticas estão trazendo resultados. Entretanto conforme as sugestões identificadas nos dados coletados, algumas políticas públicas poderiam ser estudadas e implementadas como novas linhas de financiamento com taxas de juros menores para pessoa física, a criação de um fundo de incentivo, a possibilidade de utilizar o FGTS para a instalação de placas, a instalação nos prédios públicos e um IPTU reduzido para os proprietários de imóveis que gerem energia. 
Mesmo com o incremento nesta matriz alternativa nos últimos anos, do total de energia produzida no Brasil, menos de 0,5\% vem da fonte solar, portanto tem-se ainda um enorme caminho de oportunidades e de debates sobre como incentivar ainda mais esta matriz. O incentivo deve vir precedido de políticas que fortaleçam a matriz, tendo em vista que os principais acordos internacionais sobre o clima incentivam as fontes alternativas de energia limpa.

A pesquisa possui limitação em função de levar em consideração apenas 12 atores atuantes em alguns municípios do Estado do Ceará, em função disso sugere-se novas pesquisas envolvendo, por exemplo, a capital do Estado do Ceará e outras capitais do nordeste para que sejam pesquisadas informações mais representativas desse setor que vem ganhando destaque. Sugere-se novos estudos para que abranja mais municípios e obtenha uma quantidade maior de participantes na pesquisa.

\section{Referências}

AMBIENTE ENERGIA. Ceará terá complexo fotovoltaico com sete usinas solares. 2016. Disponível em: <https://www.ambienteenergia.com.br/index.php/2016/09/ceara-tera-complexofotovoltaico-com-sete-usinas-solares/30195>. Acesso em:28 mar.2017.

ANEEL - Agencia Nacional de Energia Elétrica. Resolução Normativa $\mathbf{N}^{\circ} \mathbf{4 8 2}$, de 17 de abril de 2012: estabelece as condições gerais para o acesso de microgeração e minigeração distribuída aos sistemas de distribuição de energia elétrica, o sistema de compensação de energia elétrica, e dá outras providências. Brasília DF, 2012. Disponível em: <http://www2.aneel.gov.br/cedoc/bren2012482.pdf>. Acesso em: 09 mar.2017.

Micro e minigeração distribuída: sistema de compensação de energia elétrica. Brasília DF, 2014. 28 p.: il. - (Cadernos temáticos ANEEL). Disponível em: <https://www.neosolar.com.br/forum/media/kunena/attachments/1174/ANEEL_cadernotematico-microeminigeracao.pdf $>$. Acesso em: 09 mar.2017.

Micro e minigeração distribuída: sistema de compensação de energia elétrica. Brasília DF, 2016. 31 p.: il. - (Cadernos temáticos ANEEL). Disponível em: <http://www.aneel.gov.br/documents/656877/14913578/Caderno+tematico+Micro+e+Minigera\% C3\%A7\%C3\%A3o+Distribuida+-+2+edicao/716e8bb2-83b8-48e9-b4c8-a66d7f655161>. Acesso em: 09 mar.2017. 
Energia Solar. Brasília, Brasil, 2017. Disponível em: <http://www2.aneel.gov.br/aplicacoes/atlas/pdf/03-energia_solar(3).pdf>. Acesso em: 28 fev.2017.

BELINOVSKI, Josélia Alves da Silva. O programa leite das crianças como política pública no combate à desnutrição infantil no município de Telêmaco Borba - PR. Monografia de especialização apresentada ao Departamento Acadêmico de Gestão e Economia (DAGEE) da Universidade Tecnológica Federal do Paraná (UTFPR) / Universidade Aberta do Brasil (UAB) para título de Especialista em Gestão Pública Municipal. Curitiba, 2011. Disponível em: $<$ http://repositorio.roca.utfpr.edu.br/jspui/bitstream/1/1223/1/CT_GPM_I_2011_88.PDF>. Acesso em: 15 fev.2017.

BIASOLI, Semíramis Albuquerque. Institucionalização de políticas públicas de educação ambiental: subsídios para a defesa de uma política do cotidiano. Tese de doutorado da Escola Superior de Agricultura "Luz de Queiroz". Centro de Energia Nuclear na Agricultura. Piracicaba, 2015. Disponível em: <http://www.teses.usp.br/teses/disponiveis/91/91131/tde-11122015151307/pt-br.php>. Acesso em: 15 fev.2017.

BIGGI, Róger Renó. O uso da luz solar como fonte de energia elétrica através de sistema fotovoltaico - SF. Trabalho de conclusão de curso apresentado como parte das exigências do curso de Pós-Gradução Lato Sensu em Formas Alternativas de Energia para a obtenção do título de especialização) - da Universidade Federal de Lavras - MG, 2013. Disponível em: <http://www.solenerg.com.br/m/wp-content/uploads/2013/02/TCC-Roger.pdf >. Acesso em: 28 fev.2017.

BURSZTYN, Maria Augusta; BURSZTYN, Marcel. Fundamentos de política e gestão ambiental. Caminhos para a sustentabilidade. Rio de Janeiro: Ed. Garamond, 2013.

BURSZTYN, Marcel; RODRIGUES FILHO, Saulo. O clima em transe: vulnerabilidade e adaptação da agricultura familiar. Rio de Janeiro: Ed.Garamond, 2016.

BRASIL (A). Constituição da República Federativa do Brasil. Brasília, DF: Senado, 1988.

(B). Decreto-Lei No 31853 de 14/12/2015. Convênio ICMS 16, de 22 de abril de 2015. Disponível em: <https://www.confaz.fazenda.gov.br/legislacao/convenios/2015/cv016_15>. Acesso em 24 mar.2017.

CARVALHO, E.F.A.; CALVETTE, M.J.F. Energia Solar: um passado, um presente.... um futuro auspicioso.Rev. Virtual Quim. v.2, n.3, 192-203, 2010. Disponível em:<http://rvqsub.sbq.org.br/index.php/rvq/article/view/89/134>. Acesso em: 28 fev.2017.

CASTELLI, Ian. 5 novas tecnologias que podem revolucionar o mundo em breve. 2015.Disponível em: <https://www.tecmundo.com.br/tecnologia/88432-5-novas-tecnologiasrevolucionar-mundo.htm>. Acesso em: 28 fev.2017.

CERVO, Amado Luiz, BERVIAN, Pedro Alcino. Metodologia Científica. $5^{\text {a }}$ Edição. São Paulo: Pearson Prentice Hall, 2002. 
DAMASCENO, Claudionor Almir Soares. Políticas públicas e o direito à comunicação na América Latina: os casos do Brasil e Venezuela. Dissertação apresentada ao Programa de PósGraduação em Integração da América Latina da Universidade de São Paulo - PROLAM/SP para título de mestre. 2012. Disponível em: file:///C:/Users/ALENCAR\%202/Downloads/2012_ClaudionorAlmirSoaresDamasceno\%20(4).pd f>. Acesso em: 15 fev.2017.

ELPAÍS - O Jornal Global. Acordo de Paris: os pontos-chave do pacto sobre a mudança climática. 2016. Disponível em:

<http://brasil.elpais.com/brasil/2016/11/02/internacional/1478101060_412467.html>. Acesso em: 26 mar.2017.

GEORGESCU-ROEGEN, Nicholas. O decrescimento. São Paulo: Ed. Senac, 2012. Acesso em: 28 fev. 2017.

GOVERNO DO ESTADO DO CEARÁ. Primeira usina de energia solar é inaugurada no Ceará. 2011. Disponível em:< http://www.ceara.gov.br/sala-de-imprensa/noticias/3941-primeirausina-de-energia-solar-e-inaugurada-no-ceara>. Acesso em: 24 mar.2017.

G1.Ceará ganha primeira usina de energia solar do Brasil. 2011. Disponível em: $<$ http://g1.globo.com/ceara/noticia/2011/08/ceara-ganha-primeira-usina-comercial-de-energiasolar-do-brasil.html>. Acesso em: 28 mar.2017.

IBGE - Instituto Brasileiro de Geografia e Estatística. Redes e Fluxos do território. Logística de energia: 2015 / IBGE, Coordenação de Geografia. - Rio de Janeiro: IBGE, 2016. 102p. Disponível em: <http://biblioteca.ibge.gov.br/visualizacao/livros/liv97260.pdf>. Acesso em: 24 mar.2017.

IBGE. IBGE Cidades. Disponível em: <https://cidades.ibge.gov.br/brasil/ce/juazeiro-donorte/panorama>. Acessado em: 24 mar. 2017.

JORNAL O POVO. Acordo facilita geração solar para o comércio cearense. 2016. Disponível em:

<http://www20.opovo.com.br/app/opovo/economia/2016/11/04/noticiasjornaleconomia,3667672/ acordo-facilita-geracao-solar-para-o-comercio-cearense.shtml>. Acesso em: 28 mar.2017.

KEMERICH, Pedro Daniel da Cunha. Et al. Paradigmas da energia solar no Brasil e no mundo. Revista Eletrônica em Gestão, Educação e Tecnologia Ambiental Santa Maria, v.20, n. 1, jan.abr. 2016, p. 241-247 Revista do Centro de Ciências Naturais e Exatas - UFSM ISSN: 22361170. Disponível em: <file://CC:/Users/ALENCAR\%202/Downloads/16132-101354-1-PB\%20(2).pdf〉. Acesso em: 28 fev.2017.

KNOB, Daniel. Geração de hidrogênio por eletrólise da água utilizando energia solar fotovoltaica. Dissertação (Mestrado em Ciências na Área de Tecnologia Nuclear - Materiais) Instituto de Pesquisas Energéticas e Nucleares da Universidade de São Paulo, 2013. Disponível em: $<$ http://www.teses.usp.br/teses/disponiveis/85/85134/tde-11062014-143621/pt-br.php〉. Acesso em: 28 fev.2017.

LAVILlE, Christian; DIONNE, Jean. A construção do Saber: manual de metodologia da pesquisa em ciências humanas. Porto Alegre: Artmed; Belo Horizonte: Editora UFMG, 1999. 
MARCONI, Marina de Andrade; LAKATOS, Eva Maria. Fundamentos da Metodologia Científica. 7 eds. São Paulo: Atlas, 2010.

MALHOTRA, Naresh K. Introdução à Pesquisa de Marketing. São Paulo: Prentice Hall, 2005.

MATTAR, Fauze Najib. Pesquisa de marketing: Metodologia, planejamento. 6 ed. São Paulo: Atlas, 2005.

MC DANIEL, Carl; GATES, Roger. Pesquisa de marketing. Rio de janeiro: Thomson, 2004.

MME - Ministério de Minas e Energia. Energia solar fotovoltaica cresceu quase $\mathbf{3 0} \%$ no mundo em 2014. 2015. Disponível em:

<http://www.mme.gov.br/web/guest/pagina-inicial/outras-noticas/-

/asset_publisher/32hLrOzMKwWb/content/energia-solar-fotovoltaica-cresceu-quase-30-nomundo-em-2014>. Acesso em: 07 nov.2017.

NETO, Recieri Scarduelli. MADRUGA, Kátia Cilene Rodrigues. GEREMIAS, Reginaldo. A micro e minigeração de energia fotovoltaica distribuída como política pública para sustentabilidade. ENGEMA, Encontro Internacional Sobre Gestão Empresarial e Meio Ambiente. ISSN: 2359-1048 dezembro 2016. Disponível em: <http://engemausp.submissao.com.br/18/anais/arquivos/151.pdf >. Acesso em: 09 mar.2017.

ONU. Agenda 2030.Disponível em: <http://www.agenda2030.com.br/aagenda2030.php>. Acesso em: 26 mar. 2017.

Transformando Nosso Mundo: A Agenda 2030 para o Desenvolvimento Sustentável. Disponível em: < https://nacoesunidas.org/pos2015/agenda2030/. Acesso em: 26 mar. 2017.

PALÁCIO DO PLANALTO PRESIDENCIA DA REPÚBLICA. Saiba o que é o Acordo de Paris, ratificado pelo governo nesta segunda-feira. 2016. Disponível em: $<$ http://www2.planalto.gov.br/acompanhe-planalto/noticias/2016/09/saiba-o-que-e-o-acordo-deparis-ratificado-pelo-governo-nesta-segunda-feira>. Acesso em: 26 mar.2017.

PEREIRA, José Matias. Manual de Metodologia da Pesquisa Científica. 3 ed. São Paulo: Atlas, 2012.

PICANÇO, Jurandir. Mercado de energias renováveis e geração distribuída. 2015. Disponível em:

<file:///C:/Users/ALENCAR\%202/Downloads/fiec_mercado\%20er\%20e\%20gd_2015\%20(1).pdf >. Acesso em: 28 mar.2017.

QUEIROZ, Herminig Everson Matos. Comparação entre o Modelo Mental de Professor e o Modelo Conceitual de Sistema de Informação para Apoio ao Planejamento de Aula. Dissertação apresentada ao Programa de Pós-Graduação em Ciência da Computação do Centro de Informática da Universidade Federal de Pernambuco para obtenção do grau de Mestre Profissional em Ciência da Computação. Disponível em: <http://repositorio.ufpe.br/bitstream/handle/123456789/18708/EVERSON\%20BIBLIOTECA.pdf ?sequence=1\&isAllowed=y $>$. Acesso em: 15 nov. 2017 . 
REPÚBLICA FEDERATIVA DO BRASIL. Pretendida Contribuição Nacionalmente Determinada Para Consecução do Objetivo da Convenção-Quadro das Nações Unidas Sobre Mudança do Clima. 2017.Disponível em: <http://www.itamaraty.gov.br/images/ed_desenvsust/BRASIL-iNDC-portugues.pdf. Pág. 1-10>. Acesso em: 26 mar.2017.

RODRIGUES, Marta M. Assunção. Políticas públicas. São Paulo: Publifolha, 2010. RUA, Maria das Graças. Políticas públicas. Florianópolis: CAPES/UAB, 2009.

SEVERINO, Antônio Joaquim. Metodologia do Trabalho Científico. 24 ed. São Paulo: Cortez, 2016.

SILVA, R. M. Energia Solar no Brasil: dos incentivos aos desafios. Brasília: Núcleo de Estudos e Pesquisas/CONLEG/Senado, Fevereiro/2015 (Texto para Discussão $\mathrm{n}^{\circ}$ 166). Disponível em: <https://www12.senado.leg.br/publicacoes/estudos-legislativos/tipos-de-estudos/textos-paradiscussao/td166>. Acesso em: 15 fev.2017.

SILVA, Andressa Hennig, FOSSÁ, Maria Ivete Trevisan. Análise de Conteúdo: Exemplo de Aplicação da Técnica para Análise de Dados Qualitativos. IV Encontro de Ensino e Pesquisa em Administração e Contabilidade. Brasília/DF - 3 a 5 de novembro de 2013. Disponível em: <http://www.anpad.org.br/admin/pdf/EnEPQ129.pdf>. Acesso em: 16 maio 2017.

SOUZA, Maria Tereza Saraiva; RIBEIRO, Henrique César Melo. Sustentabilidade Ambiental: uma Meta-Análise da Produção Brasileira em Periódicos de Administração. RAC/ANPAD, 2013. Disponível em: <http://www.scielo.br/pdf/rac/v17n3/a07v17n3>. Acesso em: 16 abr.2017.

TORRES, Regina Célia. Energia solar fotovoltaica como fonte alternativa de geração de energia elétrica em edificações residenciais. Dissertação (Mestrado - Programa de PósGraduação em Engenharia Mecânica e Área de Concentração em Térmica e Fluídos) - Escola de Engenharia de São Carlos da Universidade de São Paulo, 2012. Disponível em:<http://www.teses.usp.br/teses/disponiveis/18/18147/tde-18032013-091511/pt-br.php >.

Acesso em: 28 fev.2017.

\section{Como citar este artigo (Formato ABNT):}

ALENCAR, maria P. de; ALMEIDA NETO, José Leandro de; MARANHÃO, Thércia L. G.; TAVARES, Cristiano Viana C.C. Políticas Públicas para micro e minigeração de energia solar no estado do Ceará: um estudo levando-se em consideração o contexto nacional e municípios no semiárido cearense. Id on Line Revista ultidisciplinar e de Psicologia, 2017, vol.12, n.39, p.192-223. ISSN: 1981-1179.

Recebido: 12.11.2017

Aceito: 25.11.2017 